\title{
Possible monoclinic distortion of Mo2GaC under high pressure
}

Mark Nikolaevsky, Roee Friedman, Martin Dahlqvist, Mishael Hornik, Eran Sterer, Michel W. Barsoum, Johanna Rosén, Aviva Melchior and Elad N. Caspi

The self-archived postprint version of this journal article is available at Linköping University Institutional Repository (DiVA):

http://urn.kb.se/resolve?urn=urn:nbn:se:liu:diva-165474

N.B.: When citing this work, cite the original publication.

Nikolaevsky, M., Friedman, R., Dahlqvist, M., Hornik, M., Sterer, E., Barsoum, M. W., Rosén, J., Melchior, A., Caspi, E. N., (2020), Possible monoclinic distortion of Mo2 $\mathrm{GaC}$ under high pressure, Journal of Applied Physics, 127(14), 145103. https://doi.org/10.1063/1.5140182

Original publication available at:

https://doi.org/10.1063/1.5140182

Copyright: AIP Publishing

http://www.aip.org/ 


\title{
Possible monoclinic distortion of $\mathrm{Mo}_{2} \mathrm{GaC}$ under high pressure
}

Mark Nikolaevsky, ${ }^{1, *}$ Roee Friedman, ${ }^{2}$ Martin Dahlqvist, ${ }^{3}$ Michael Hornik, ${ }^{2}$ Eran Sterer, ${ }^{1}$ Michel W. Barsoum, ${ }^{4}$ Johanna Rosen, ${ }^{3}$ Aviva Melchior, ${ }^{1}$ El'ad N. Caspi ${ }^{1,4, *}$

${ }^{1}$ Physics Department, Nuclear Research Centre-Negev, POBox 9001, 84190 Beer-Sheva, Israel

${ }^{2}$ Israel Atomic Energy Commission, POBox 7061, 61070 Tel-Aviv, Israel

${ }^{3}$ Department of Physics Chemistry and Biology, Linköping University, SE-581 83 Linköping, Sweden

${ }^{4}$ Department of Materials Science and Engineering, Drexel University, Philadelphia PA 19104, USA

* Corresponding authors: El'ad N. Caspi, eladc@iaec.gov.il; Mark Nikolaevsky, marknster@gmail.com

\begin{abstract}
In this work, we present a high-pressure diffraction results of the Mo-based MAX phase, $\mathrm{Mo}_{2} \mathrm{GaC}_{\mathrm{C}} \mathrm{A}$ diamond anvil cell was used to compress the material up to $30 \mathrm{GPa}$, and X-ray diffraction was used to determine the structure and unit cell parameters as a function of pressures. Somewhat surprisingly, we find that at $295 \pm 25 \mathrm{GPa}$, the bulk modulus of $\mathrm{Mo}_{2} \mathrm{GaC}$ is the highest reported of all the MAX phases measured to date. The c/a ratio increases with increasing pressure. At above $15 \mathrm{GPa}$, a splitting in the $\left(\begin{array}{lll}1 & 0 & 0\end{array}\right)$ reflection occurs. This result, coupled with new DFT calculations, show that a second order phase transition to possibly a mixture of a hexagonal and monoclinic structures may explain this splitting. Such experimentally and theoretically supported phase transition was not predicted in previously published calculations.
\end{abstract}




\section{Introduction}

With over 150 members, the $\mathrm{M}_{\mathrm{n}+1} \mathrm{AX}$ (MAX) phases with $\mathrm{n}=1-3$ are a large class of layered, machinable, hexagonal, nanolaminated materials, where $\mathrm{M}$ is an early transition metal, $\mathrm{A}$ is the main group element, and $\mathrm{X}$ is $\mathrm{C}$ or $\mathrm{N}$ [1-5]. They are characterized by carbide or nitride slabs $\left(\mathrm{M}_{n+1} \mathrm{X}_{\mathrm{n}}\right)$ separated by pure A monolayers. Having this layered structure, the MAX phases exhibit a combination of the beneficial properties of both ceramic and metallic compounds, making them attractive for many technological applications [4], such as machinable thermal shock resistance refractories [6], high temperature heating elements [7], neutron irradiation resistant parts for the nuclear industry [8]. Moreover, with the discovery of MXenes [9], MAX phases' 2D derivatives, the variety of possible applications vastly increased to the fields of energy storage [10], electronics, sensors, and more [11].

Out of this large family of compounds, $\mathrm{Mo}_{2} \mathrm{GaC}$ is one of few having Mo as the sole occupant of the M-site [12,13]. It was first synthesized in 1967 and found to be superconducting below $\sim 4 \mathrm{~K}$ [14]. Some theoretical studies were published in recent years regarding its physical properties at ambient pressure with the goal of linking the observed superconductivity to calculated electronic properties [15-17]. When compared to the isostructural Ga-containing phases $\left(\mathrm{Nb}_{2} \mathrm{GaC}\right.$ and $\left.\mathrm{V}_{2} \mathrm{GaC}\right)$ it is predicted to have the highest bulk, B, and lowest shear, G, modulus, and that its compressibility along the $c$ axis is smaller than along the $a$ axis [15]. When compared to five other superconducting MAX phases $\left(\mathrm{Nb}_{2} \mathrm{AC}\right.$ with $\mathrm{A}=\mathrm{S}, \mathrm{Sn}, \mathrm{As}$, and $\mathrm{In}$, and $\left.\mathrm{Ti}_{2} \mathrm{InC}\right) \mathrm{Mo}_{2} \mathrm{GaC}$ was predicted to have the highest bulk modulus ( $\sim 249 \mathrm{GPa}$ ) and the second largest shear modulus ( $\sim 96 \mathrm{GPa})$ [16]. The combination of high bulk modulus, machinability, and interesting electronic properties makes $\mathrm{Mo}_{2} \mathrm{GaC}$ a worthy candidate for further study and characterization.

Quite recently, the elastic properties and structural evolution under pressure of $\mathrm{Mo}_{2} \mathrm{GaC}$ were calculated by first-principles [18]. As in Ref. [15], a substantial difference in the compressibilities along the different axes was found with the $a$ axis predicted to be significantly softer than the $c$ axis. Moreover, it was shown that internal coordinate shifts of the Mo atoms is closely reflected by the $c$ axis compressibility anomaly that showed three different slopes within 0-15 GPa, 20-60 GPa, and 70-100 GPa, respectively [18]. Importantly, no phase transition as a function of pressure is reported. Ab initio calculations in $\mathrm{Zr}_{2} \mathrm{InC}$ above $70 \mathrm{GPa}$ [19] and in $\mathrm{Ti}_{2} \mathrm{GaN}$ between $350 \mathrm{GPa}$ and $600 \mathrm{GPa}$ [20] show a similar abnormal c axis behavior. In the first example, as oppose to $\mathrm{Mo}_{2} \mathrm{GaC}$, the $\mathrm{c}$ axis is softer than the a axis, apart from the anomaly. In the later example the anomaly is much broader, and the c/a ratio is extremely large, compared to other examples in this review. In both cases this abnormal behavior only occurs at very large pressures, beyond the scope of this work. These behaviors were found to be as a result of a similar coordinate shifts in the corresponding $\mathrm{M}$-site in the $\mathrm{M}_{2} \mathrm{AX}$ phase. 
In recent experimental work, $\mathrm{Hu}$ et al. described a method for the rapid synthesis of $\mathrm{Mo}_{2} \mathrm{GaC}$, shortening its preparation time from 4 weeks to about a day [12]. During the course of that work, $\mathrm{Mo}_{2} \mathrm{Ga}_{2} \mathrm{C}$ was discovered and later characterized [21,22]. With two Ga layers between the $\mathrm{Mo}_{2} \mathrm{C}$ layers, the $\mathrm{Mo}_{2} \mathrm{Ga}_{2} \mathrm{C}$ structure is quite similar to that of $\mathrm{Mo}_{2} \mathrm{GaC}$ with only one $\mathrm{Ga}$ layer.

The interest in high-pressure properties of the MAX phase family of compounds resulted in various measurement campaigns in the past decade. A summary of such previously published studies is given in Table 1.

Table 1: Summary of response of different MAX phases to hydrostatic pressure. The table includes the bulk moduli, B, and their derivatives as a function of pressure, the maximal pressure reached in the experiment and the trends of the ratios between the $c$ and $a$ axes with increasing pressure. The measurement technique was X-ray diffraction (XRD) for all entries.

\begin{tabular}{|c|c|c|c|c|}
\hline $\begin{array}{c}\text { Phase } \\
\text { [ref.] }\end{array}$ & $\begin{array}{c}\text { Fitted Bulk } \\
\text { modulus } \\
\text { [GPa] }\end{array}$ & $\begin{array}{c}\text { Fitted Bulk } \\
\text { Modulus } \\
\text { derivative }\end{array}$ & $\begin{array}{c}\text { Max. } \\
\text { pressure } \\
\text { [GPa] }\end{array}$ & c/a ratio \\
\hline $\mathrm{Zr}_{2} \operatorname{InC}[23]$ & $127 \pm 5$ & $4.3 \pm 0.3$ & 52 & Decreases \\
\hline $\mathrm{Ti}_{2} \operatorname{InC}[24]$ & $148 \pm 3$ & $4.20 \pm 0.04$ & 53 & Decreases \\
\hline $\mathrm{Ti}_{2} \mathrm{SnC}[24]$ & $152 \pm 3$ & $3.90 \pm 0.06$ & 49 & $*$ \\
\hline $\mathrm{Nb}_{2} \mathrm{SnC}[24]$ & $180 \pm 5$ & 4 (fixed) & 49 & $*$ \\
\hline $\mathrm{Hf}_{2} \mathrm{SnC}[24]$ & $169 \pm 4$ & 4 (fixed) & 50 & Decreases \\
\hline $\mathrm{Ti}_{2} \mathrm{AlC}[\mathbf{2 5 , 2 6 ]}$ & $186 \pm 2$ & $4.0 \pm 0.1$ & 54 & $*$ \\
\hline $\mathrm{Ti}_{2} \mathrm{AlN}$ [26] & $169 \pm 3$ & $3.5 \pm 0.2$ & 45 & Decreases \\
\hline $\mathrm{V}_{2} \mathrm{AlC}[25]$ & $201 \pm 3$ & $4.0 \pm 0.1$ & 46 & $*$ \\
\hline $\mathrm{Cr}_{2} \mathrm{AlC}[25]$ & $165 \pm 2$ & $4.1 \pm 0.1$ & 50 & Increases \\
\hline $\mathrm{V}_{2} \mathrm{GeC}$ [27] & $165 \pm 2$ & 4 (fixed) & 50 & $*$ \\
\hline $\mathrm{Cr}_{2} \mathrm{GeC}$ [27] & $182 \pm 2$ & 4 (fixed) & 50 & * \\
\hline $\mathrm{Nb}_{2} \mathrm{AlC}[25]$ & $209 \pm 2$ & $3.9 \pm 0.1$ & 36 & Increases \\
\hline $\mathrm{Ta}_{2} \mathrm{AlC}[25]$ & $251 \pm 2$ & $4.5 \pm 0.2$ & 45 & Approx. 1 \\
\hline $\mathrm{Cr}_{2} \mathrm{GaC}[28]$ & $188 \pm 5$ & $3.6 \pm 0.3$ & 50 & Approx. 1 \\
\hline $\mathrm{Ti}_{2} \mathrm{GaN}[28]$ & $189 \pm 4$ & $3.5 \pm 0.3$ & 46 & Decreases \\
\hline $\mathrm{Ta}_{4} \mathrm{AlC}_{3}[29]$ & $261 \pm 2$ & $3.8 \pm 0.2$ & 47 & Approx. 1 \\
\hline $\mathrm{Ti}_{4} \mathrm{AlN}_{3}[30]$ & $216 \pm 2$ & $3.84 \pm 0.06$ & 55 & Decreases \\
\hline $\mathrm{Ti}_{3} \mathrm{GeC}_{2}[\mathbf{3 1}]$ & $197 \pm 2$ & $3.4 \pm 0.1$ & 51 & Decreases \\
\hline$\left(\mathrm{Ti}_{0.5}, \mathrm{~V}_{0.5}\right)_{2} \mathrm{AlC}[\mathbf{3 2}]$ & $183 \pm 3$ & 4 (fixed) & 47 & Approx. 1 \\
\hline$\left(\mathrm{Ti}_{0.5}, \mathrm{Nb}_{0.5}\right)_{2} \mathrm{AlC} \mathrm{[32]}$ & $181 \pm 3$ & 4 (fixed) & 53 & Decreases \\
\hline $\mathrm{Ti}_{3}\left(\mathrm{Si}_{0.5} \mathrm{Ge}_{0.5}\right) \mathrm{C}_{2}[\mathbf{3 3}]$ & $183 \pm 4$ & $3.4 \pm 0.2$ & 53 & Decreases \\
\hline
\end{tabular}




\begin{tabular}{ccccl}
\hline $\mathrm{Ti}_{3} \mathrm{Al}\left(\mathrm{C}_{0.5} \mathrm{~N}_{0.5}\right)_{2}[\mathbf{3 4}]$ & $219 \pm 4$ & $3.7 \pm 0.3$ & 50 & Decreases \\
$\mathrm{Ti}_{3}\left(\mathrm{AlSn}_{0.2}\right) \mathrm{C}_{2}[\mathbf{3 4}]$ & $226 \pm 3$ & 4 (fixed) & 50 & Decreases \\
$\left(\mathrm{Ti}_{0.5} \mathrm{Zr}_{0.5}\right)_{2} \operatorname{InC}[\mathbf{2 4}]$ & $131 \pm 3$ & $3.80 \pm 0.05$ & 50 & Decreases \\
\hline
\end{tabular}

* The behavior of the $\mathrm{c}$ axis changes as the pressure increases while the a axis remains more or less unchanged. At lower pressures the c/a ratio decreases $\left(\mathrm{Ti}_{2} \mathrm{InC}, \mathrm{Nb}_{2} \mathrm{InC}, \mathrm{V}_{2} \mathrm{GeC}, \mathrm{V}_{2} \mathrm{AlC}\right.$ and $\left.\mathrm{Ti}_{2} \mathrm{AlC}\right)$ or remains the same $\left(\mathrm{Cr}_{2} \mathrm{GeC}\right)$ and above a certain pressure the c/a ratio increases.

Close examination of Table 1 leads to several general conclusions regarding the behavior of MAX phases under pressure. First and foremost, no symmetry changes have been reported up to the highest (mostly $\sim 50 \mathrm{GPa}$ ) studied pressures. Second, from the fitted results, the B values seem to differ quite substantially between different MAX phases from a low of $\sim 127 \mathrm{GPa}$ for $\mathrm{Zr}_{2} \mathrm{InC}$, to a high of $\sim 261 \mathrm{GPa}$ for $\mathrm{Ta}_{4} \mathrm{AlC}_{3}$. The pressure derivatives, on the other hand, were more or less constant at $\approx 4$ for all phases. Third, in the overwhelming majority of the studied cases, the $c$ axis is softer than the $a$ axis, especially at lower pressures. Importantly, as noted above, Gao et al. [18] predicted the opposite for $\mathrm{Mo}_{2} \mathrm{GaC}$ as found below.

Herein, we report on the high-pressure XRD measurement of $\mathrm{Mo}_{2} \mathrm{GaC}$ up to $30 \mathrm{GPa}$. Moreover, we theoretically re-examine the high-pressure behavior predicted in previous theoretical work for $\mathrm{Mo}_{2} \mathrm{GaC}$. The experimental and theoretical results are then compared.

\section{Methods}

A detailed description of sample preparation is given elsewhere [12]. In short, it was fabricated by heating a 1:1.4 molar ratio of $\mathrm{Mo}_{2} \mathrm{C}$ and pure $\mathrm{Ga}$ to $900{ }^{\circ} \mathrm{C}$ for $24 \mathrm{~h}$ under flowing argon, Ar. Excess $\mathrm{Ga}$ was dissolved using $\mathrm{HCl}$. A small sample of that powder was remeasured at ambient conditions using a low noise Bruker D8 - advanced type diffractometer at the Nuclear Research Centre - Negev (NRCN), Israel. Using $\mathrm{CuK} \alpha$ radiation, an angular range from $20^{\circ}$ to $100^{\circ}$ was covered in steps of $0.01^{\circ}$. For the highpressure measurements, the same powder was loaded into a 301 steel gasket placed in a Tel-Aviv design Diamond Anvil Cell (DAC) [35] with a pair of $500 \mu \mathrm{m}$ culet sized diamond anvils. A Brilliant cut and a Bohler-Almax design (BA) anvils were used [36]. Ar was cryogenically loaded into the cell to act as a pressure medium and ruby spheres were placed on the sample to be used as a pressure calibrant. A Bruker micro-focus X-ray source ( $\mathrm{I} \mu \mathrm{S} 3.0)$ at the NRCN, with a Mo anode, created a $0.7107 \AA$ monochromatic Xray beam that was focused on the sample. The beam FWHM, at the focal point, was $110 \mu \mathrm{m}$. A 2D-CMOS detector was used to measure the diffraction pattern, and the DAC was placed with the BA anvil facing the detector to obtain a $70^{\circ}$ aperture (i.e. a $2 \theta$ range of $0-35^{\circ}$ ). The entire setup was held on a $2 \theta$ stage. For 
comparison purposes one ambient pressure run without $\mathrm{DAC}$ was undertaken on the $\mathrm{I} \mu \mathrm{S} 3.0$ at a $2 \theta$ range of $0 \sim 60^{\circ}$.

The systematic uncertainties in determining lattice parameters and pressure were evaluated using several standards ( $\mathrm{LaB}_{6}, \mathrm{Al}_{2} \mathrm{O}_{3}$ and $\mathrm{Au}$ ) runs in 0 to $95 \mathrm{GPa}$ range, resulting in typical values of $\sim 0.1 \%$, and $\sim 5 \%$, respectively, for the entire pressure range. Instrument resolution functions were also determined in these runs. The peak profile was chosen to be Thompson-Cox-Hastings pseudo-voight convolution were the contribution of the instrument is a constant width of the Gaussian and no cosine contribution to the Lorentzian [37]. The $\mathrm{Mo}_{2} \mathrm{GaC}$ powder was measured during both compression (7 pressure points) and decompression (20 pressure points), with a wait of at least $0.3 \mathrm{~h}$ at each pressure point. Each measurement took 10 minutes. The diffraction pattern did not change as a function of time. In this work the maximum pressure reached was $30 \mathrm{GPa}$. All diffraction patterns were analyzed by the Rietveld method [38], using the FULLPROF code [39].

All first-principles calculated energies were obtained using the Vienna Ab initio Simulation Package (VASP 5.4.4) [40] implementation of density functional theory (DFT), using the Perdew-Burke-Ernzerhof (PBE) generalized gradient approximation [41] description of the exchange-correlation energy. The plane wave energy cutoff was set at $520 \mathrm{eV}, k$-point grids with a spacing of $0.05 \AA^{-1}$ according to the MonkhorstPack method [42]. The electronic energy convergence threshold is set to $10^{-6} \mathrm{eV} /$ atom for energy and $10^{-2}$ $\mathrm{eV} / \mathrm{A}$ for force.

Two different approaches were used to calculate the possible structures; (a) relaxation of structures at various volumes, and (b) relaxation at a given applied pressure. In the first approach we allow complete relaxation of lattice parameters, unit cell shape, and internal coordinates at a static volume. In the second approach we applied an isostatic pressure while relaxing the lattice parameters, unit cell shape, and internal coordinates to the various considered symmetries.

\section{Results}

Rietveld analysis of the XRD pattern at ambient conditions measured using the Bruker D8 diffractometer (Figure 1a) showed that most reflections agree with a hexagonal symmetry (space group $P 6_{3} / m m c$ ) and lattice parameters $\mathrm{a} \sim 3 \AA$, and $\mathrm{c} \sim 13 \AA$. All the major peaks are attributable to the $\mathrm{Mo}_{2} \mathrm{GaC}$ phase. Additional reflections were observed, which agree with the existence of two minor phases, $\mathrm{Mo}_{2} \mathrm{C}$, and $\mathrm{Mo}_{2} \mathrm{Ga}_{2} \mathrm{C}$. A model containing the above mentioned three phases was fit to the data using the Rietveld analysis method. The major $\mathrm{Mo}_{2} \mathrm{GaC}$ phase was assumed to have the $P 6_{3} / m m c$ hexagonal structure with Mo, Ga, and $\mathrm{C}$ positioned in the $4 f(1 / 3,2 / 3, \mathrm{z} \approx 0.58), 2 c(1 / 3,2 / 3,1 / 4)$, and $2 a(0,0,0)$, respectively. The refined weight percentages of the phases were $\sim 78$ wt. $\% \mathrm{Mo}_{2} \mathrm{GaC}, \sim 15$ wt. $\% \mathrm{Mo}_{2} \mathrm{C}$ [43], and $\sim 7$ wt. $\% \mathrm{Mo}_{2} \mathrm{Ga}_{2} \mathrm{C}$. 
The $a$ and $c$ lattice parameters of $\mathrm{Mo}_{2} \mathrm{GaC}$ were refined as 3.0328(4) $\AA$, and 13.194(2) $\AA$, respectively. We note the small difference in the XRD results between what is presented here and in Ref. [12]. In their work, $\mathrm{Hu}$ et al. did not refine the XRD pattern with $\mathrm{Mo}_{2} \mathrm{Ga}_{2} \mathrm{C}$ as an additional impurity phase, which is the most probable reason for this discrepancy (see Figure 3 in Ref. [12]). A similar measurement is shown in figure $1 \mathrm{~b}$ taken with the $17 \mathrm{KeV}$ Bruker XRD I $\mu \mathrm{S}$ at ambient pressure. With $\mathrm{a}=3.028(3) \AA$ and $\mathrm{c}=13.195(2) \AA$ the lattice parameters of $\mathrm{Mo}_{2} \mathrm{GaC}$ determined by the $\mathrm{I} \mu \mathrm{S}$ instrument are in excellent agreement with the ones determined using the high-resolution diffractometer. A small difference is observed in the impurity weight percentages determined by the $\mathrm{I} \mu \mathrm{S}$ instrument were $\mathrm{Mo}_{2} \mathrm{C}$ was found to amount for $\sim 12 \mathrm{wt} . \%$ and $\mathrm{Mo}_{2} \mathrm{Ga}_{2} \mathrm{C} \sim 6 \mathrm{wt} . \%$. This small difference is probably due to the higher background of the latter instrument were the sample size is much smaller.

$\mathrm{XRD}$ patterns as a function of pressure in the range ambient to $30 \mathrm{GPa}$ are presented in Figure 2. From ambient and up to $15.7(8) \mathrm{GPa}$, a stable hexagonal structure $\left(\mathrm{P}_{3} / \mathrm{mmc}\right)$ with a clear compression of the unit cell (Figure 2) is identified. For these patterns, Rietveld refinement analysis was performed assuming the major $\mathrm{Mo}_{2} \mathrm{GaC}$ MAX phase has the ambient $P 6_{3} / m m c$ hexagonal structure, with starting values of $a, c$, and $\mathrm{z}$ as in the ambient XRD analysis described above. Structural parameters of the two minor impurity phases, $\mathrm{Mo}_{2} \mathrm{C}$, and $\mathrm{Mo}_{2} \mathrm{Ga}_{2} \mathrm{C}$, were also refined, using their structural models from Refs. [43], and [22], respectively, as the starting ones. $\alpha-\mathrm{Fe}$ and $\varepsilon-\mathrm{Fe}$, resulting from the steel gasket of the DAC, were also considered, before and after the Fe phase transition. Their previously published structures as a function of pressure were fixed in the analysis [44]. XRD patterns as a function of pressure above 15.7(8) GPa clearly show splitting of the ( $\left(\begin{array}{lll}1 & 0 & 0\end{array}\right)$ reflection of the major phase (Figure 2). This splitting increases with pressure, suggesting a deviation from the typical MAX phase hexagonal structure. 

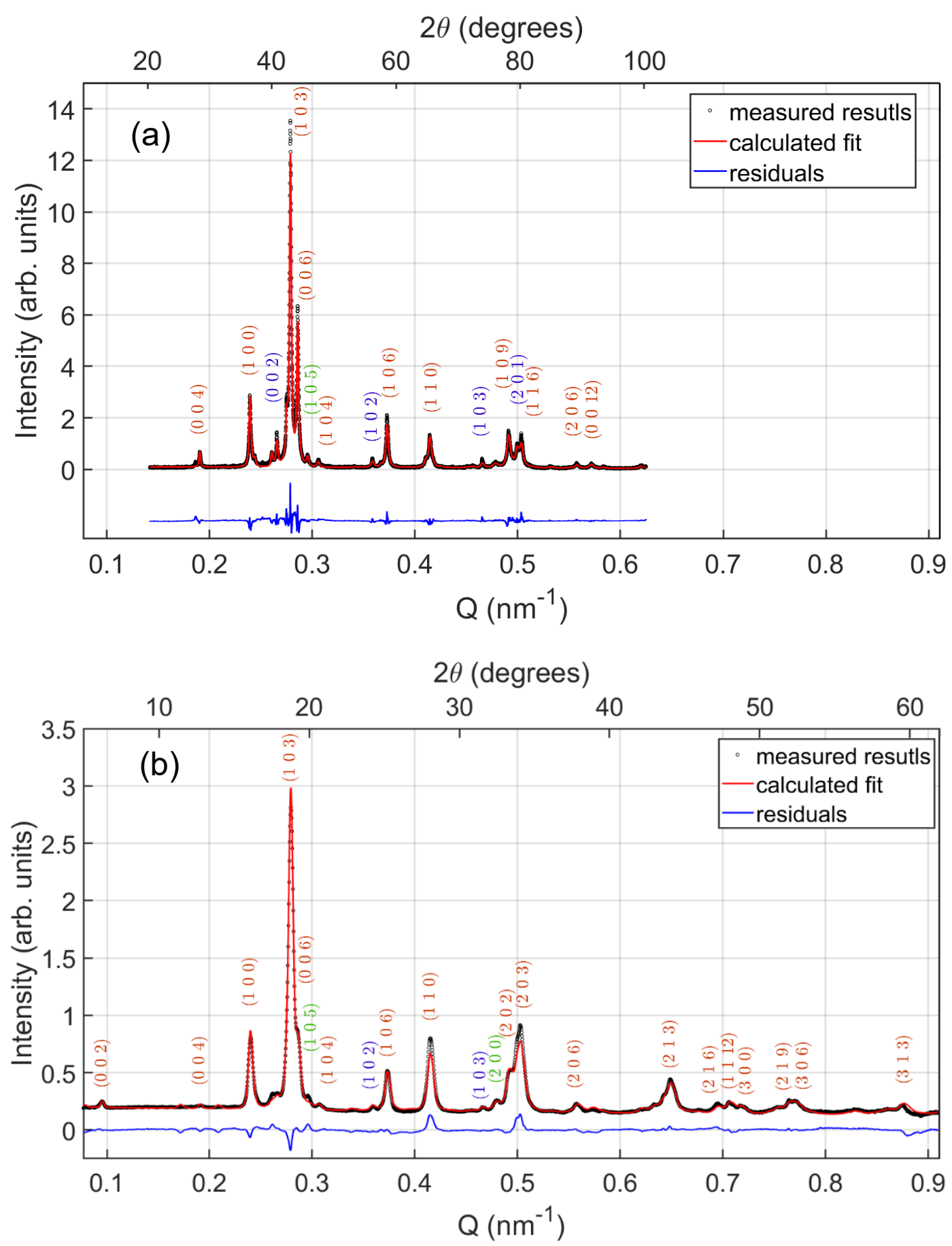

Figure 1: Rietveld analysis of the XRD pattern of $\mathrm{Mo}_{2} \mathrm{GaC}$ at ambient pressure using the hexagonal $\left(P 6_{3} / m m c\right)$ structure (see text). The ambient pressure diffractograms are obtained using the (a) Bruker D8 - advanced type diffractometer with $\mathrm{CuK} \alpha$ radiation, and (b) Bruker $\mathrm{I} \mu \mathrm{S}$ diffractometer with MoK $\alpha$ radiation. Data (black circles) are taken from experiment performed; the red line represents the calculated pattern that included the major MAX phase (red indices) as well as the $\mathrm{Mo}_{2} \mathrm{C}$ (blue indices) and $\mathrm{Mo}_{2} \mathrm{Ga}_{2} \mathrm{C}$ (green indices) impurity phases. The blue line represents the residual curve between the measured data and the fitted model. 


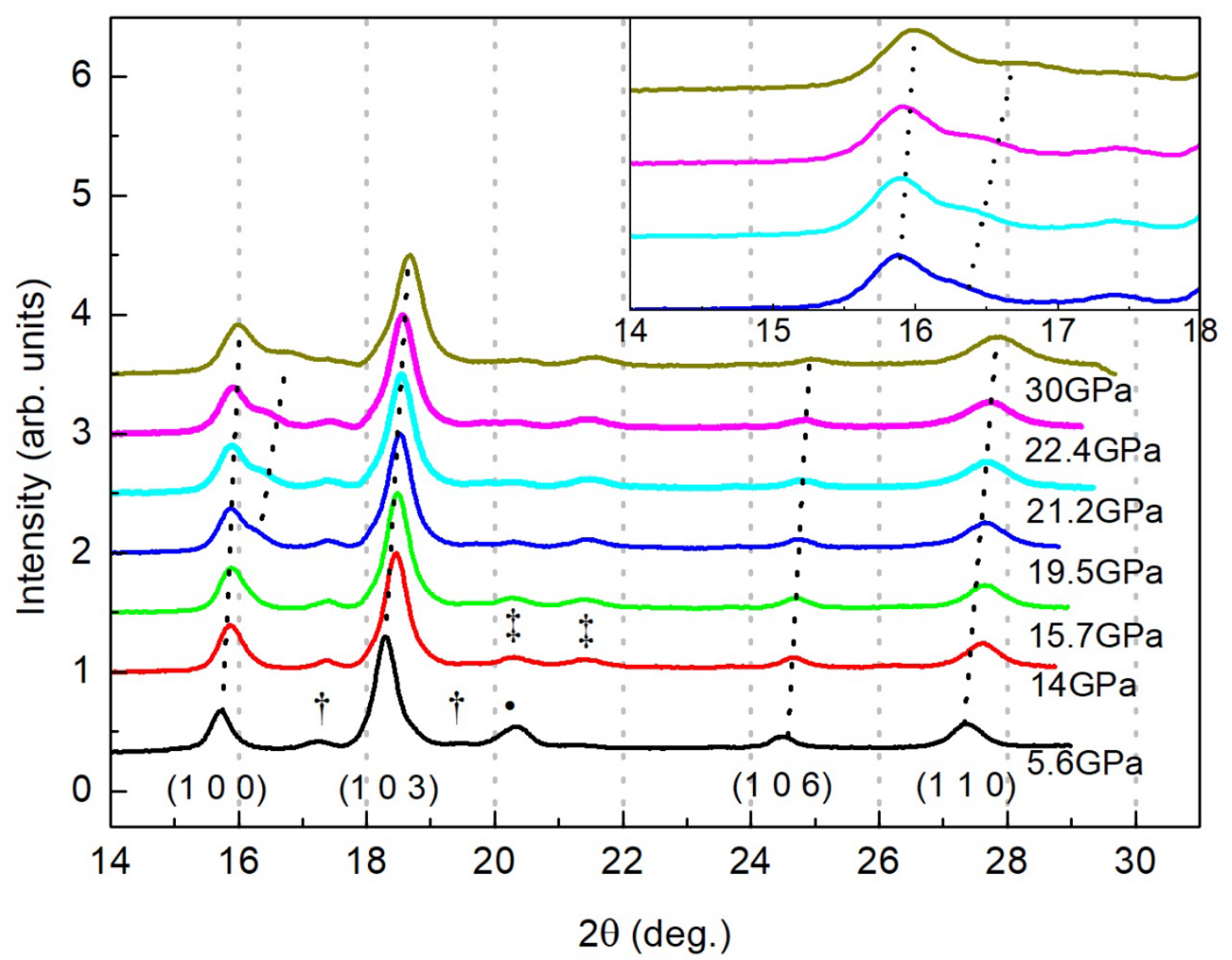

Figure 2: Effect of hydrostatic pressure on XRD patterns of $\mathrm{Mo}_{2} \mathrm{GaC}$. Main reflections are denoted by their Miller indices. A splitting of the $\left(\begin{array}{lll}1 & 0 & 0\end{array}\right)$ reflection is clearly observed at around $16^{\circ}$ above $15.7 \mathrm{GPa}$ and develops as the pressure increases. Reflections belonging to $\mathrm{Mo}_{2} \mathrm{Ga}_{2} \mathrm{C}, \mathrm{Fe} \alpha$ and $\varepsilon$ phases are marked with daggers, dots, and double dagger, respectively. Of note is the splitting of reflections that occurs in the $\mathrm{Mo}_{2} \mathrm{Ga}_{2} \mathrm{C}$ phase, similar to that of the major phase. The maximum pressure reached was $30 \mathrm{GPa}$. The inset depicts the area of the $\left(\begin{array}{lll}1 & 0 & 0\end{array}\right)$ split between $14^{\circ}$ and $18^{\circ}$.

\section{DFT Calculations}

Following the clear evidence of splitting of the original hexagonal $\left(\begin{array}{lll}1 & 0 & 0\end{array}\right)$ line, as well as the evidence for the relative similarity of the low-pressure and high-pressure structures, it was assumed that the best candidate structures to describe the high-pressure range of $\mathrm{Mo}_{2} \mathrm{GaC}$ should either be the orthorhombic, or monoclinic structures that are related to the original $P 6_{3} / m m c$ structure by isomorphic super-group/subgroup relation [45]. Eleven different symmetries were considered (Figure 3). They include the following: The typical MAX phase with $P 6_{3} / m m c(\alpha)$ symmetry depicted in Figure 3a, denoted $\alpha$ to distinguish it from $\beta$ in Figure $3 b$ [46]; additional monoclinic and hexagonal symmetries (Figure 3c-g); and symmetries 
retrieved by combining the $P 6_{3} / m m c(\alpha)$ with $P 6_{3} / m m c(\beta)$ where the notation in parenthesis indicates the stacking sequence of $\alpha$ and $\beta$ symmetries within the unit cell (Figure 3 h-k).

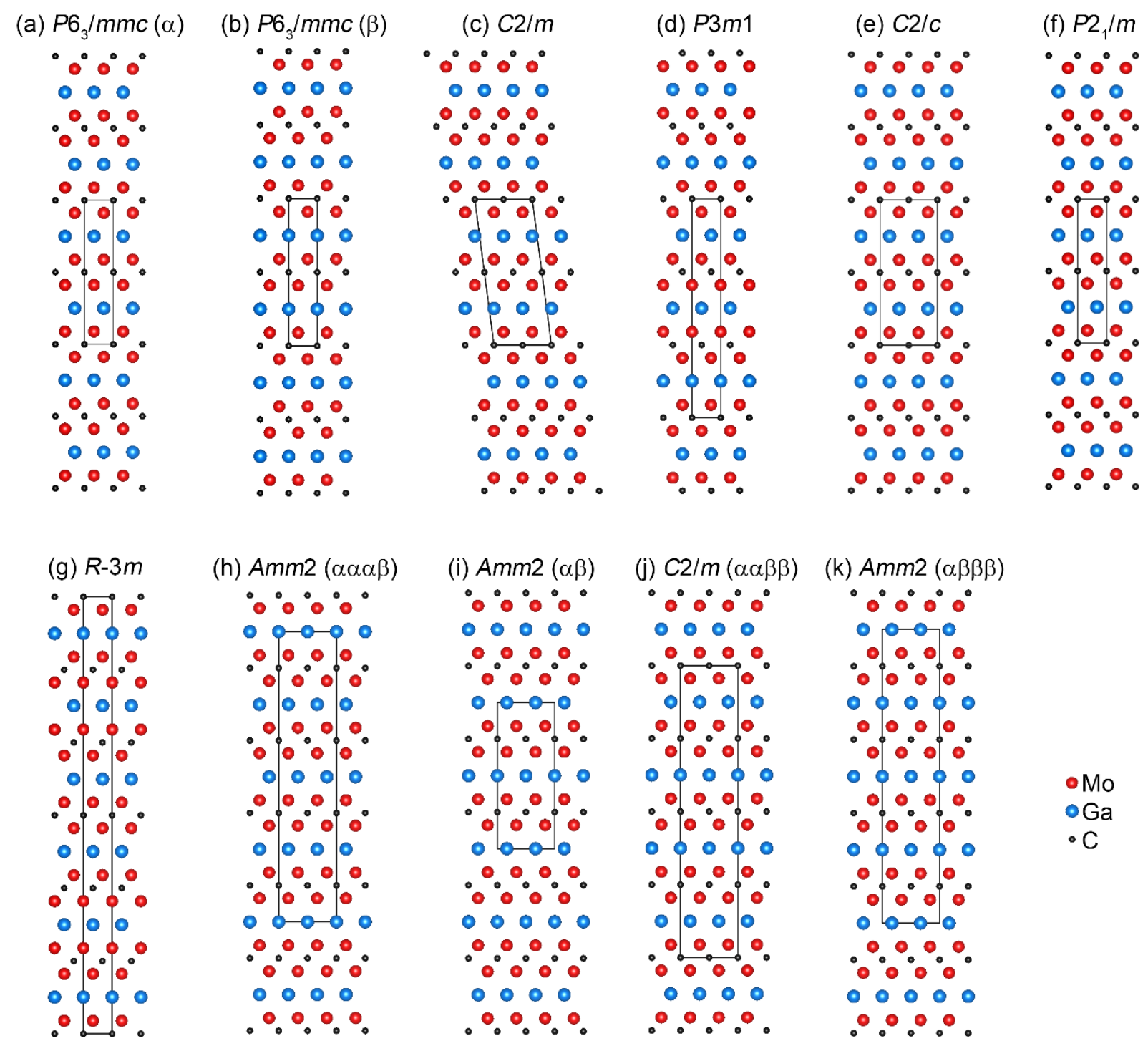

Figure 3: Considered crystal symmetries for $\mathrm{Mo}_{2} \mathrm{GaC}$ where the unit cells are indicated by black quadrangle. (a) shows the common hexagonal MAX phases structure $P 6_{3} / m m c$; (b) the modified hexagonal structure $P 6_{3} / m m c(\beta)$. (d), and (g) show trigonal structures, (h), (i), and (k) orthorhombic, and (c), (e), and (j) monoclinic. 
The results for the volume relaxation method are shown in Figure 4. Figure 4a depicts the calculated total energy as a function of volume per atom for the eleven considered symmetries shown in Figure 3. All are very close in energy despite the various stacking symmetries. For the volume range considered, the structures with $C 2 / c$ and $P 2_{1} / m$ symmetries, (e) and (f) in Figure 3, relaxes to the original MAX phase $P 6_{3} / m m c$ symmetry. Figure $4 \mathrm{~b}$ shows the relative enthalpy change $\Delta H$, with respect to $P 6_{3} / m m c(\alpha)$, as function of pressure, $p$, using:

$$
\Delta H=H-H\left(P 6_{3} m m c(\alpha)\right),
$$

where $H$ is given by:

$$
H(V)=E(V)+p V=E(V)+\frac{\delta E}{\delta V} V,
$$

and $E(\mathrm{~V})$ is the calculated energy at volume $\mathrm{V}$.

Up to $\sim 9 \mathrm{GPa}$, the initial $P 6_{3} / m m c$ symmetry possesses the lowest enthalpy. Above $12 \mathrm{GPa}$ $P 6_{3} / m m c(\beta)$ is favored. In between there is a structure which has C-Mo-Ga-Mo-C subunits with alternating $\alpha$ and $\beta$ symmetries. This intermediate structure is thus a hybrid of the structures below $9 \mathrm{GPa}$ and above $12 \mathrm{GPa}$.
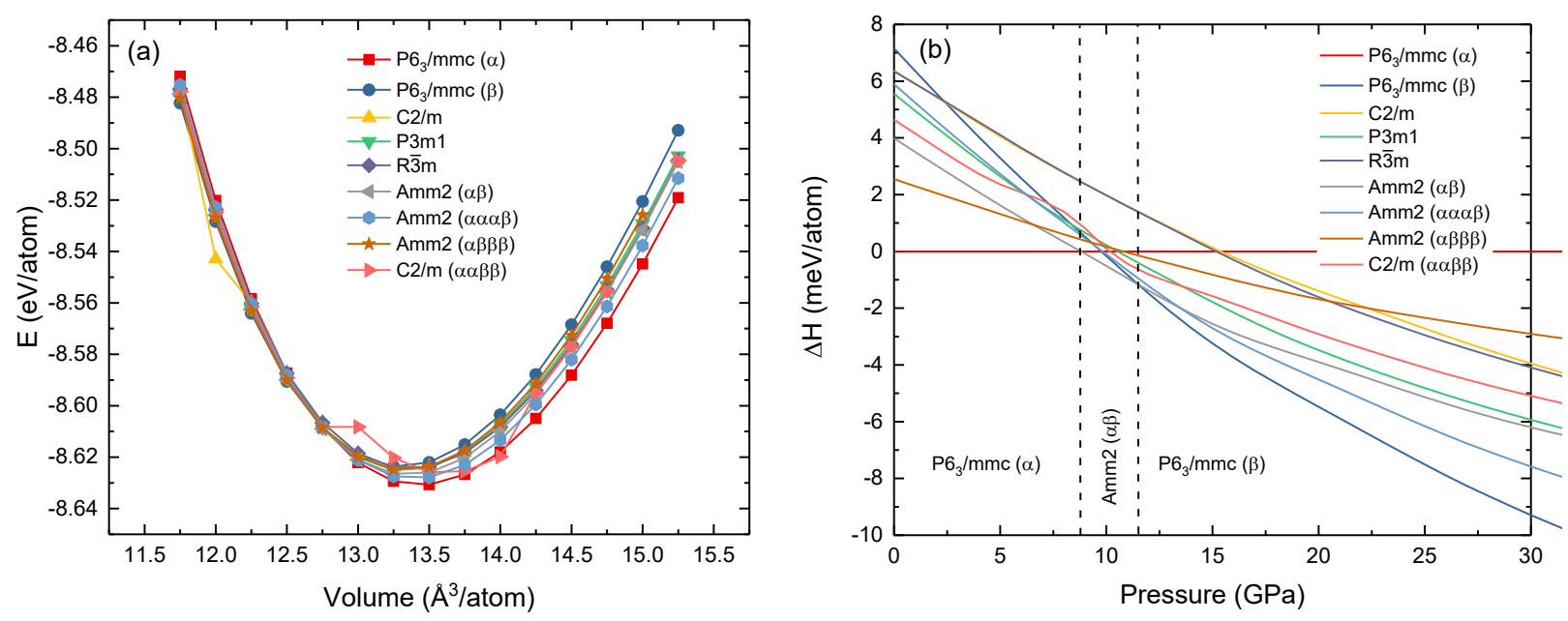

Figure 4: (a) Calculated energy as function of volume and (b) enthalpy change with respect to $P 6_{3} / m m c$ $(\alpha)$ as function of pressure for the considered symmetries in Figure 3.

In the pressure relaxation approach very similar results were obtained, qualitatively and quantitatively. The results of the enthalpy change as a function of pressure for the pressure relaxation method are shown in Figure 5. 


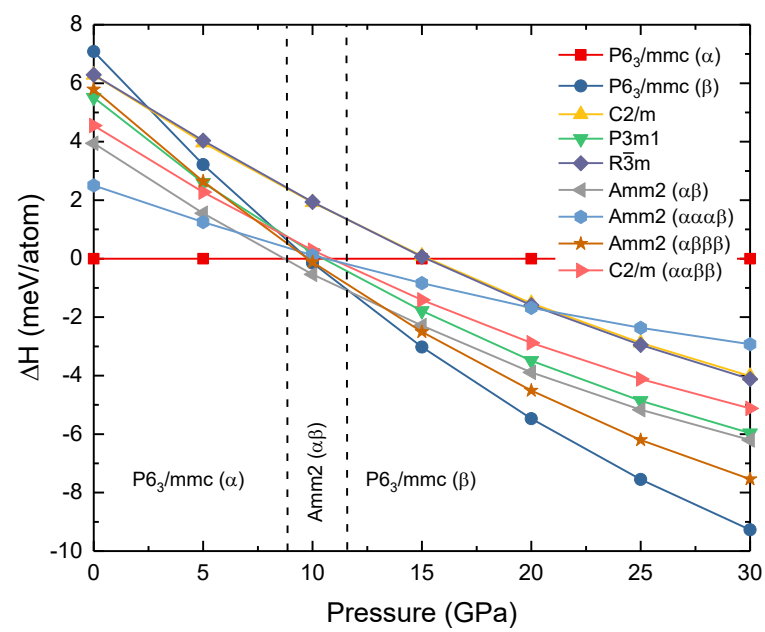

Figure 5: Enthalpy change with respect to $P 6_{3} / m m c(\alpha)$ as function of pressure for the considered symmetries in figure 3 in the pressure relaxation method.

The calculated structural parameters for the nine inequivalent symmetries considered are shown in Figure 6, together with previously calculated results [18]. To allow clear comparison between the various symmetries having different out-of-plane extensions, we chose to present a normalized lattice parameter extending over two $\mathrm{Mo}_{2} \mathrm{C}$ layers as in Figure 3(a). As the pressure increases both $a$ and $c$ decrease for all considered symmetries. Compressibility ratio in Figure 6(c) demonstrates that the compressibility of the $a$ axis is higher than the $c$ axis in agreement with previous calculations [18]. Note that for $P 6_{3} / m m c$, the decrease in $c$ is less within 15 to $20 \mathrm{GPa}$, while $a$ decrease more within the same pressure range. Correspondingly, the compressibility ratio for $P 6_{3} / m m c$ thus show an increased slope within this pressure range. Of note is the generally good agreement between our results and those published previously in the case of the $P 6_{3} / m m c(\alpha)$ structure [18]. 

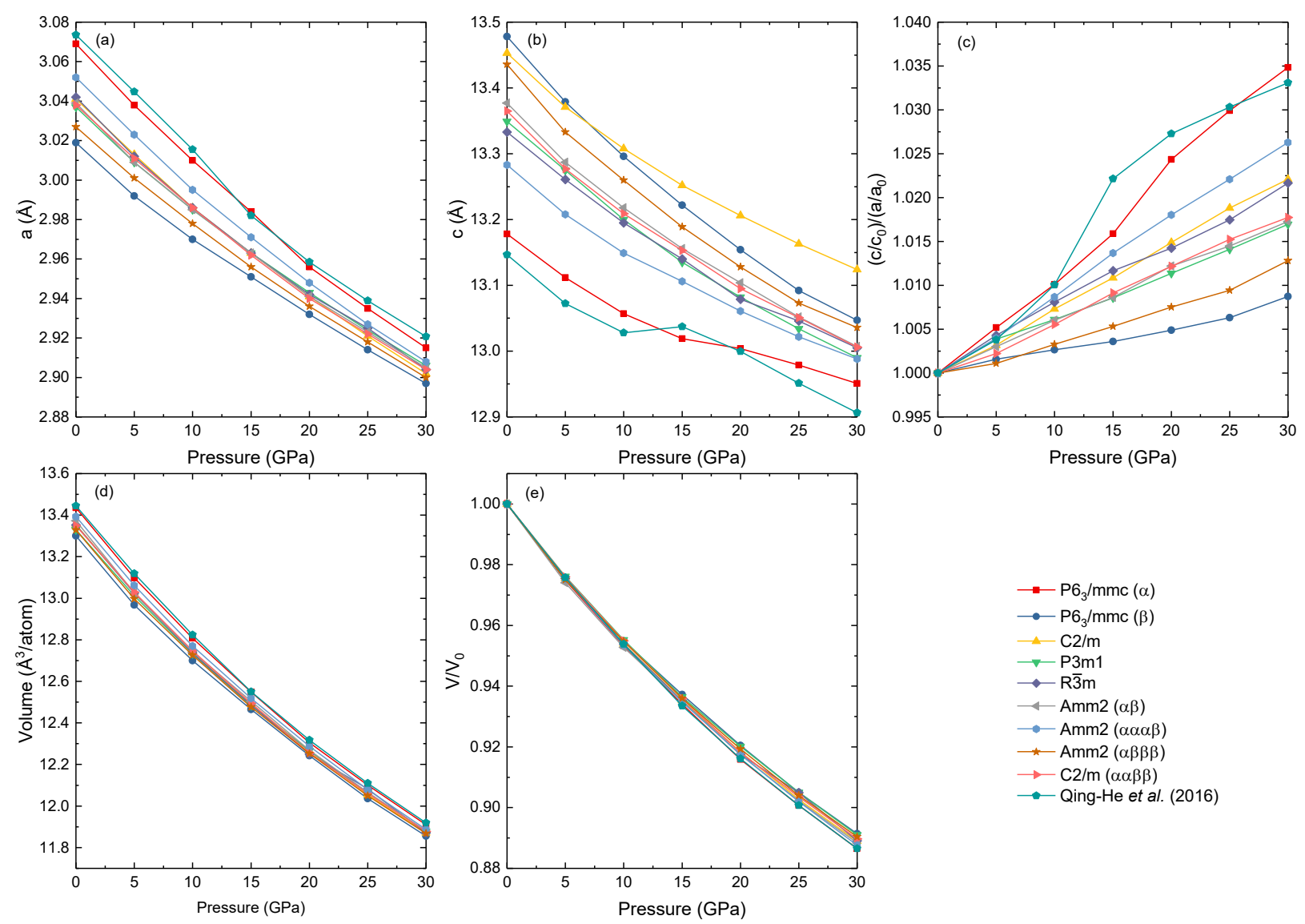

Figure 6. Calculated structural parameters (a) a, (b) c, (c) ratio between normalized - by values at ambient pressure - of $\mathrm{c}$ and a axes, volume per atom, and (f) volume normalized by values at ambient pressure for considered symmetries in Figure 3. Cited data (pentagons) were reproduced from [G. Qing-He, X. Zhi-Jun, T. Ling, L. Jin, D. An, G. Yun-Dong, and Y. Ze-Jin, Journal of Applied Physics 119, 015901 (2016).], with the permission of AIP Publishing.

\section{Analysis and Discussion}

\section{V. a. $\quad$ Analysis using $P 6_{3} / m m c$}

At low-pressures, the results show good agreement with the known hexagonal model fitted with three added impurity phases, $\mathrm{Mo}_{2} \mathrm{C}, \mathrm{Mo}_{2} \mathrm{Ga}_{2} \mathrm{C}$ and $\alpha$-Fe. At $5.6 \mathrm{GPa}$, the lowest measured pressure point upon compression, the fit reached agreement factors with values of $\chi^{2}=95.8, R_{w p}=9.2$, and $R_{\exp }=0.94$ (Figure 7). Attempting to evaluate the impurity concentration results in much lower values than expected from the ambient pressure measurements for both $\mathrm{Mo}_{2} \mathrm{C}(0.99 \pm 0.01 \mathrm{wt} \%)$ and $\mathrm{Mo}_{2} \mathrm{Ga}_{2} \mathrm{C}(1.31 \pm 0.23 \mathrm{wt} \%)$. This could be explained by the high-pressure peak broadening of the main $\mathrm{Mo}_{2} \mathrm{GaC}$ phase and the minor phases, as well as to the limited measured $\mathrm{Q}$ range $(\mathrm{Q}=\sin \theta / \lambda)$. Moreover, as the pressure increases the ability to fit the impurity models is more difficult. The compression and decompression measured cell 
parameters up to $\sim 16 \mathrm{GPa}$ coincide and show that the compressibility of the a axis is higher than the $\mathrm{c}$ axis in agreement with calculations both in the present work (figure 8) and previously published [18].

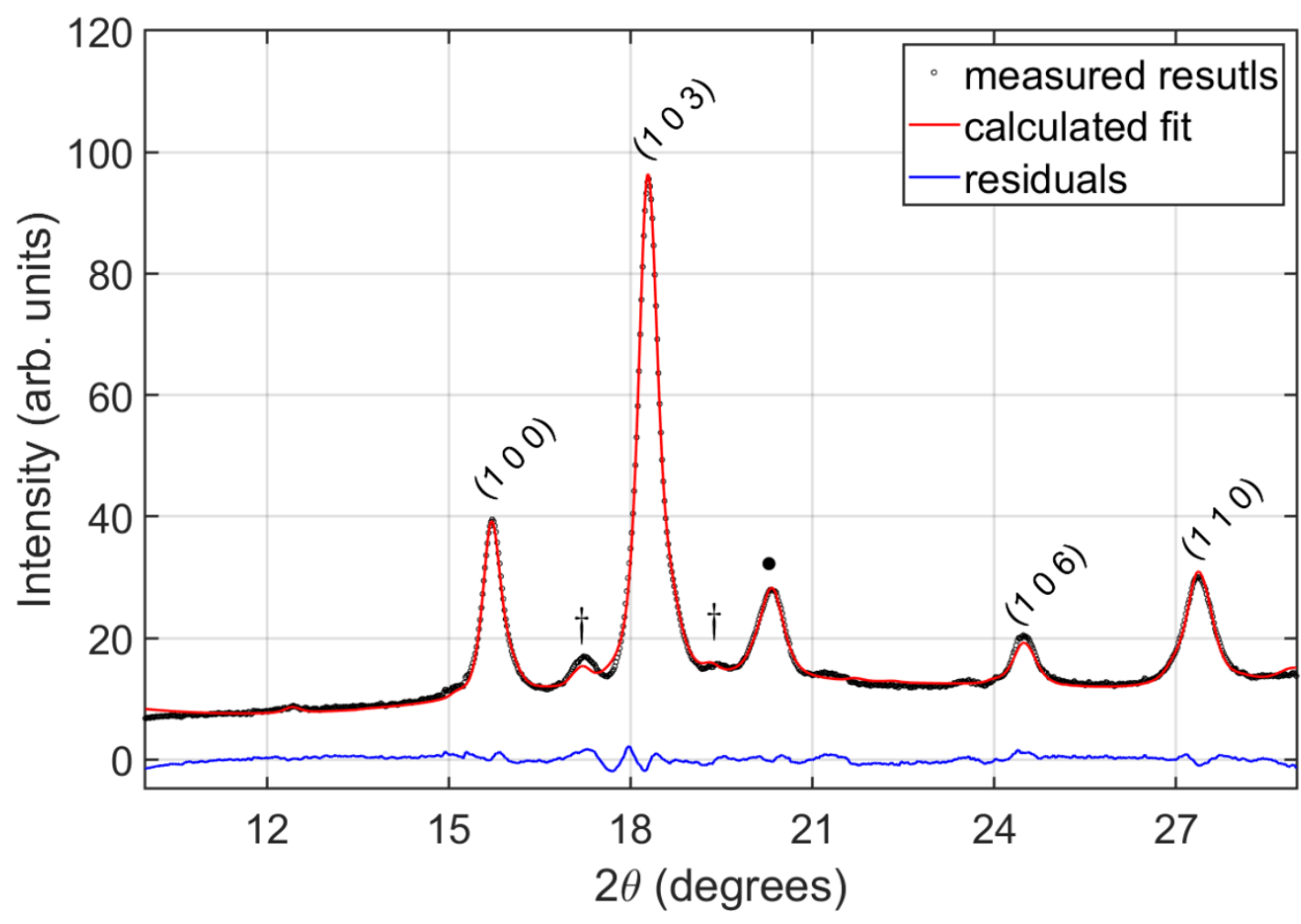

Figure 7: Rietveld analysis of $\mathrm{Mo}_{2} \mathrm{GaC}$ at $5.6 \mathrm{GPa}$. The model (red line) fitted to the data (black circles) consisted of the main $\mathrm{Mo}_{2} \mathrm{GaC}$ phase (of which main reflections are indexed) with three added impurity phases, $\mathrm{Mo}_{2} \mathrm{C}$ (not marked), $\mathrm{Mo}_{2} \mathrm{Ga}_{2} \mathrm{C}$ (dagger), and $\alpha$-Fe (black dot). The residual between the measured data and the fit is presented by the blue line at the bottom.

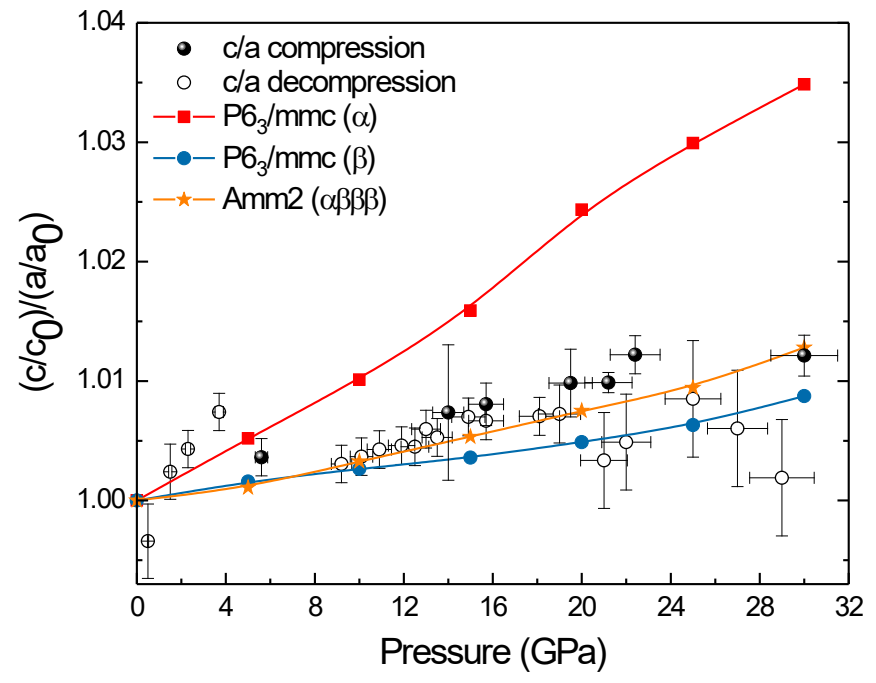


Figure 8: Ratio between normalized - by values at ambient pressure - of $c$ and $a$ axes. The measured data (black spheres and circles) were obtained by Rietveld refinement of the XRD patterns under pressure, assuming the hexagonal $\mathrm{PC}_{3} / \mathrm{mmc}(\alpha)$ structure and normalized using the ambient pressure lattice parameters assuming the same structure (see text). The measured results are compared to selected calculated results from Figure 6c (solid lines with symbols). From the results, it is clear that the a axis is more compressible than the $\mathrm{c}$ axis, as predicted.

An attempt to refine the same hexagonal model, used for pressures $\leq 15.7(8) \mathrm{GPa}$ to higher pressure values resulted in increasingly worse agreement factors reaching values of $\chi^{2}=1290, R_{\mathrm{wp}}=27.3$, and $R_{\exp }$ $=0.76$ at $30 \mathrm{GPa}$. The most serious discrepancy between data and model resulted from the splitting of the hexagonal $\left(\begin{array}{lll}1 & 0 & 0\end{array}\right)$ reflection (Figure 9). A demonstration of attempts to refine the hexagonal model to the angle range of the original hexagonal $\left(\begin{array}{lll}1 & 0 & 0\end{array}\right)$ reflection at 20 and $30 \mathrm{GPa}$ is shown in Figure 9(c)\&(d). They are clearly poor.
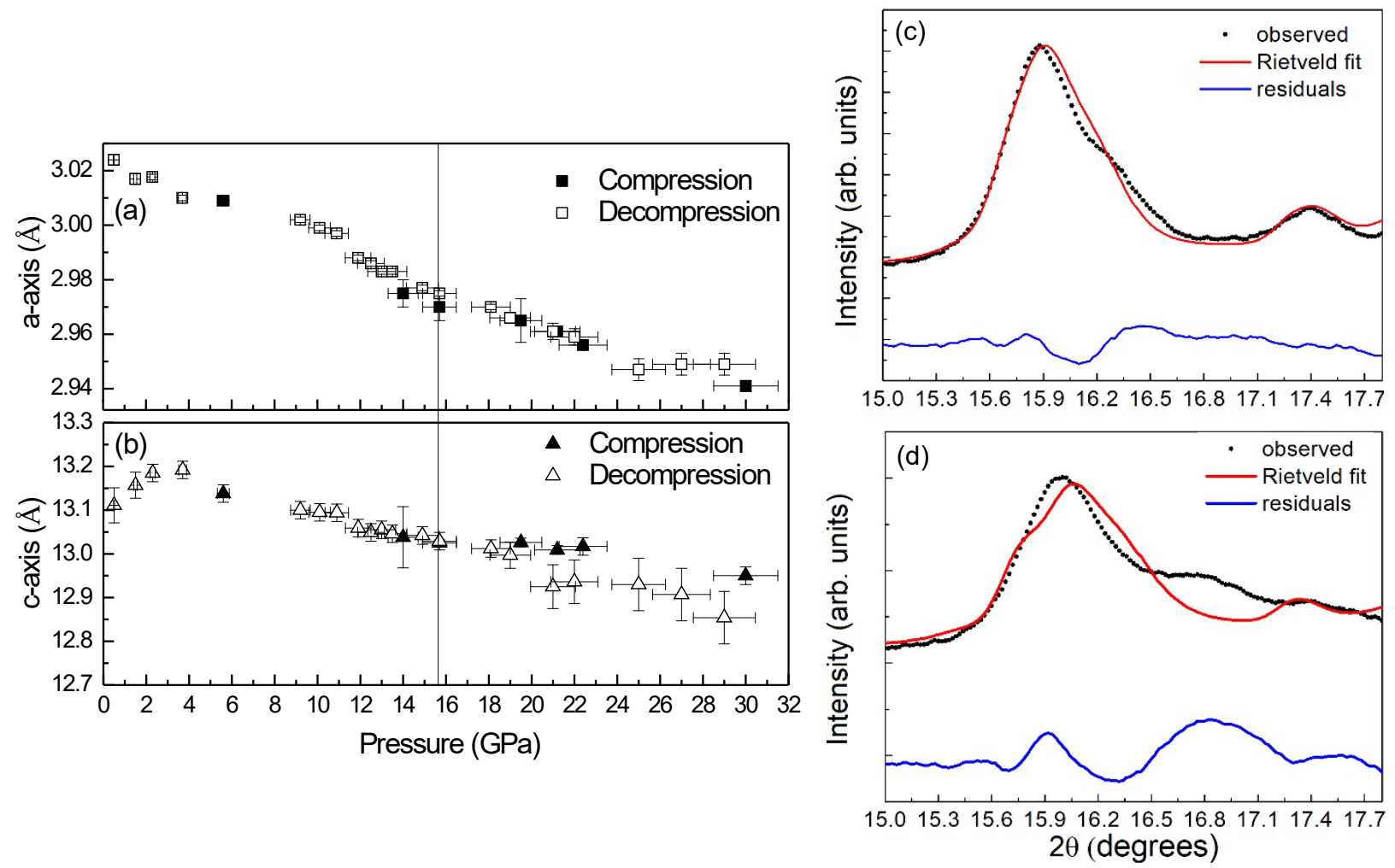

Figure 9: Analysis of diffraction patterns as a function of pressure using the P6/mmc (194) symmetry. (a) $a$ lattice parameter and, (b), $c$ lattice parameter. Rietveld analyses of results at (c) $20 \mathrm{GPa}$ and (d) $30 \mathrm{GPa}$ assuming no change in symmetry. The vertical line in (a) and (b) represents the pressure after which refinement using the hexagonal symmetry gives poor fit agreement factors. 
Of note is the apparent reversibility of this symmetry distortion. Upon decompression, the lattice symmetry returns to the low-pressure hexagonal phase at approximately $15 \mathrm{GPa}$. In addition, when we closely examine the lattice parameters when fitting the hexagonal model to the entire pressure range (Figure 9), no noticeable change of slope is observed at $\sim 15 \mathrm{GPa}$, within the accuracy of our analysis. Moreover, as will be shown below, the lattice parameters values for pressures $>16 \mathrm{GPa}$, resulting from the analysis using the hexagonal structure, agree well with the average of the lattice parameters values that resulted from analyses using lower symmetries. These two observations indicate that the structure at high-pressure, is a slightly distorted symmetry of the original hexagonal one, which in turn, suggests a second order phase transition.

An additional important observation that stands out from Figure 8 is the quantitative agreement between the measured lattice parameters ratio and the calculated one using Amm2 ( $\alpha \beta \beta \beta)$ for pressures above $\sim 8 \mathrm{GPa}$. It is clear that the lattice parameters ratio favors a lower than hexagonal crystal symmetry, which is also predicted to be more stable at higher pressures.

\section{V.b. $\quad$ Analysis using lower symmetries}

Following the DFT calculations, that show possible lower (than hexagonal) symmetry for pressures above $15 \mathrm{GPa}$, the data in this pressure region was analyzed using each one of the eleven calculated symmetries including the monoclinic symmetries, $P{ }_{1} / m$ and $C 2 / c$, that were found in the calculations to relax back to the $P 6_{3} / m m c$ structure. As starting models, the structures in Figure 3 with their corresponding calculated values are used. Even though the $\beta-P 6_{3} / m m c$ structure (Figure $3 b$ ) was found to be the most stable structure among those calculated it was dismissed as it failed to explain the splitting at high-pressure. Refinement of all other structures was attempted. However, full atomic positions refinement of the structures presented in Figure 3f-i was impossible due to the large number of degrees of freedom in their atomic sites. Out of the three remaining structures (Figure 3c-e) the only symmetry that was fully refined in the entire high-pressure range was $C 2 / m$. Albeit these limitations, that probably rise from the broadening of the peaks at high pressures and Q-range limits of the instrument used, it is important to compare the results of these three relatively similar structures to those achieved assuming hexagonal symmetry. The fitted structural parameters of the $C 2 / \mathrm{m}, C 2 / \mathrm{c}$ and $P 2_{1} / \mathrm{m}$ models to the $30 \mathrm{GPa}$ data (see Figure 10 for $C 2 / \mathrm{m}$, and $C 2 / c$ ) are summarized in Table 2 . The fitted structural parameters of the hexagonal model to the same data is also given for comparison. 
Table 2: Rietveld refined structural parameters of four different candidate models to the $30 \mathrm{GPa}$ XRD pattern of $\mathrm{Mo}_{2} \mathrm{GaC}$.

\begin{tabular}{|c|cccc|}
\hline & $\mathrm{P}_{3} / \mathrm{mmc}(194)$ & $\mathrm{P} 2_{1} / \mathrm{m}(11)$ & $\mathrm{C} 2 / \mathrm{c}(15)$ & $\mathrm{C} 2 / \mathrm{m}(12)$ \\
\hline $\mathrm{a}(\AA)$ & $2.941(2)$ & $2.972(7)$ & $2.913(1)$ & $2.967(5)$ \\
\hline $\mathrm{b}(\AA)$ & - & $2.929(5)$ & $5.145(1)$ & $5.036(1)$ \\
\hline $\mathrm{c}(\AA)$ & $12.95(2)$ & $12.83(2)$ & $12.989(7)$ & $12.87(3)$ \\
\hline$\beta / \gamma($ Degrees $)$ & - & $119.9(2)$ & $89.9(4)$ & $90.4(3)$ \\
\hline Volume/atom $\left(\AA^{3}\right)$ & $12.12(3)$ & $12.11(5)$ & $12.17(4)$ & $12.03(6)$ \\
\hline
\end{tabular}

By comparing the fitted parameters of the three monoclinic phases to the original hexagonal phase, there is no obvious difference in the relative uncertainties. The results for the monoclinic phases seem to partly explain the splitting of the $\left(\begin{array}{lll}1 & 0 & 0\end{array}\right)$ peak at pressures $<20 \mathrm{GPa}$, but at higher pressures, closer to 30 $\mathrm{GPa}$, attempting to fit either one of the $P 2_{1} / m, C 2 / m$ or the $C 2 / c$ models to the data, results again in poor agreement (Figure 10). From the three candidates, the best fit at $30 \mathrm{GPa}$ is the $C 2 / c$ structure even though none of the proposed structures fully resolve the structure of the high-pressure phase. In all cases, the values of the angles $\beta$ for $P{ }_{1} / m$ or $\gamma$ for $C 2 / c$ and $C 2 / m$ do not change from their original values above the calculated uncertainty, meaning that the angle of the monoclinic structure barely changes with increasing pressure.

The most prominent change seen for all attempts to refine with monoclinic symmetry is the obvious split between lattice parameters; a change in the a and b axes lengths. While one parameter seems to barely change its value, the other parameter rapidly decreases with increasing pressure. Moreover, as we refine the results using the monoclinic structures at lower pressures, closer to $15 \mathrm{GPa}$, the values of the $\mathrm{a}$ and $\mathrm{b}$ axes converge back to a single axis, similar to the hexagonal phase.

Overall, the calculated atomic volumes seem to behave similarly in all the phase candidates and the behavior as a function of pressure also remains the same during the phase transition. The fitted $\mathrm{a}, \mathrm{b}$ and $\mathrm{c}$ parameters of the $\mathrm{C} 2 / \mathrm{c}$ and $C 2 / m$ phases are shown in Figure 11. 

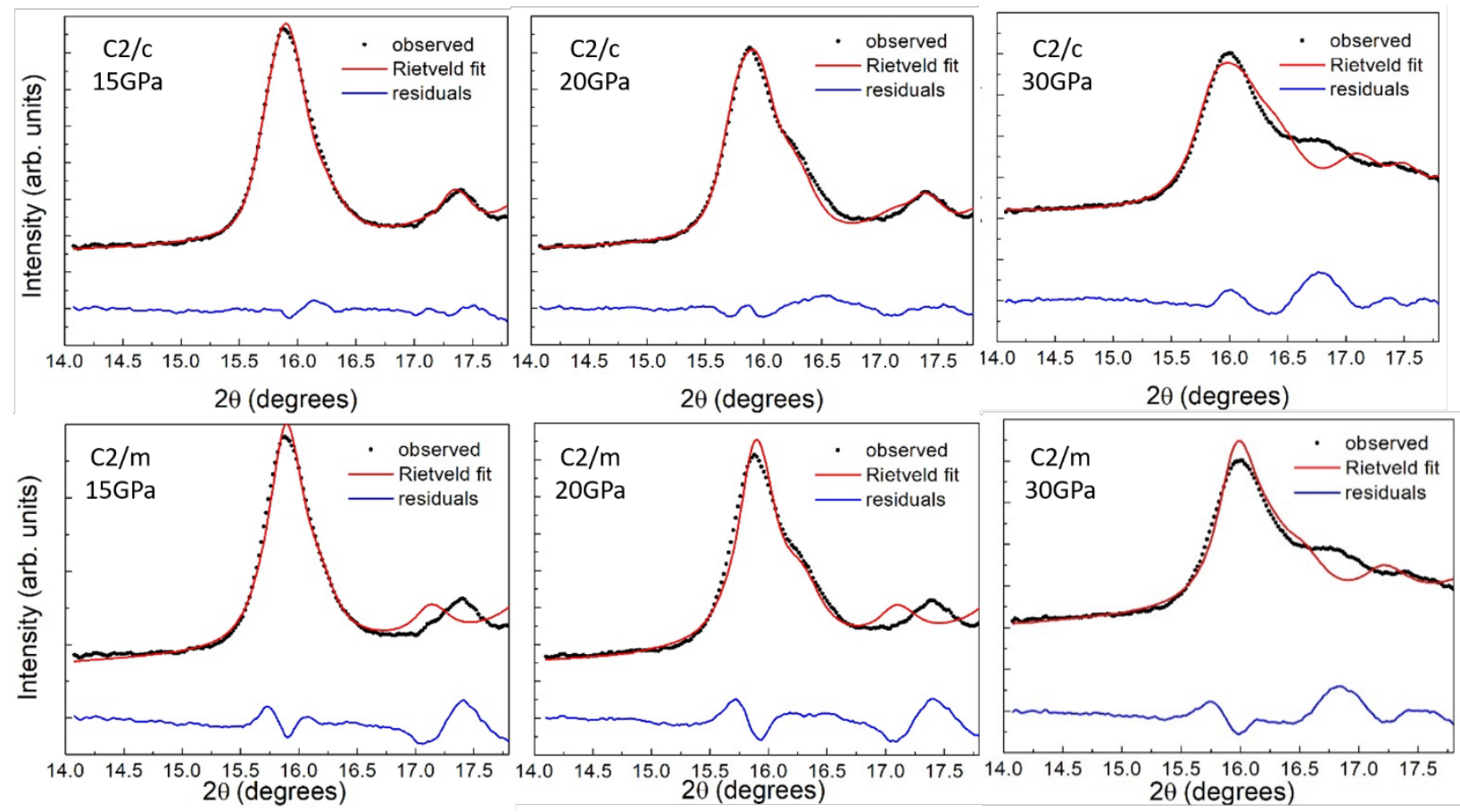

Figure 10: Fitted XRD patterns zoomed in on the $\left(\begin{array}{lll}1 & 0 & 0\end{array}\right)$ reflection splitting at $15 \mathrm{GPa}, 20 \mathrm{GPa}$ and $30 \mathrm{GPa}$ displayed from left to right. Top row is a fit to the $\mathrm{C} 2 / \mathrm{c}$ structure and the bottom row is a fit to $\mathrm{C} 2 / \mathrm{m}$ structure.
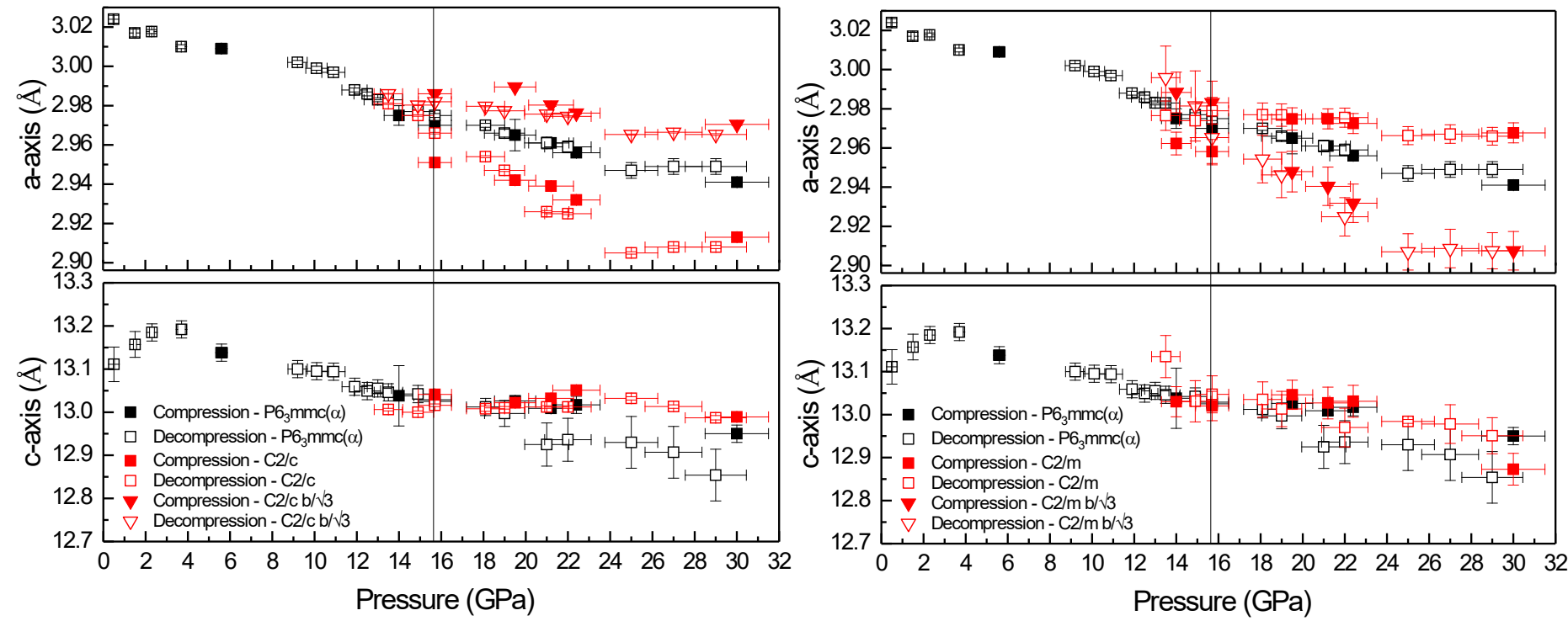

Figure 11: a, b, and c unit cell parameters as a function of pressure, refined by fitting the $C 2 / c$ structure (left column), and $C 2 / m$ (right column) to the XRD patterns. The vertical lines represent the pressure after which refinement using the hexagonal symmetry gives poor fit agreement factors. 
One could possibly argue that the $\left(\begin{array}{lll}1 & 0 & 0\end{array}\right)$ splitting is an artifact of the $\mathrm{Mo}_{2} \mathrm{Ga}_{2} \mathrm{C}$ contamination. Yet, attempting to fit the diffraction at $30 \mathrm{GPa}$ to the $\mathrm{Mo}_{2} \mathrm{GaC}$ hexagonal phase and the $\mathrm{Mo}_{2} \mathrm{Ga}_{2} \mathrm{C}$ low-pressure hexagonal phase did not result in a good fit as the splitting is too large for a $10 \%$ contamination. Moreover, $\mathrm{Mo}_{2} \mathrm{Ga}_{2} \mathrm{C}$ was reported to have a phase transition to a $P-3 m 1$ symmetry above $22 \mathrm{GPa}$ [47], and this structure was attempted to fit to the result as well, with even less success compared to when the original symmetry used for that impurity. Another possible explanation is the coexistence of both the monoclinic and the low-pressure hexagonal structures. Figure 12 depicts the fitted diffraction pattern to a mixed phase structure of both the monoclinic $C 2 / \mathrm{m}$ phase and the hexagonal phase, the refinement factors achieved from the Rietveld analysis are $\chi^{2}=255, \mathrm{R}_{\mathrm{wp}}=11.9$, and $\mathrm{R}_{\exp }=0.75$. This analysis did not include any of the impurities, but the iron. With the impurities the refinement did not converge. Attempting to fit the hexagonal phase with the $C 2 / c$ phase or the $P 2_{1} / m$ phase did not converge either with, or without, impurities. This mixture is the best candidate for the $\mathrm{HP}$ structure of $\mathrm{Mo}_{2} \mathrm{GaC}$, but due to the peak broadening at high pressures it is impossible to conduct a full analysis as a function of pressure, especially around the transition point where the differences between the phases are practically negligible (Figure 11).

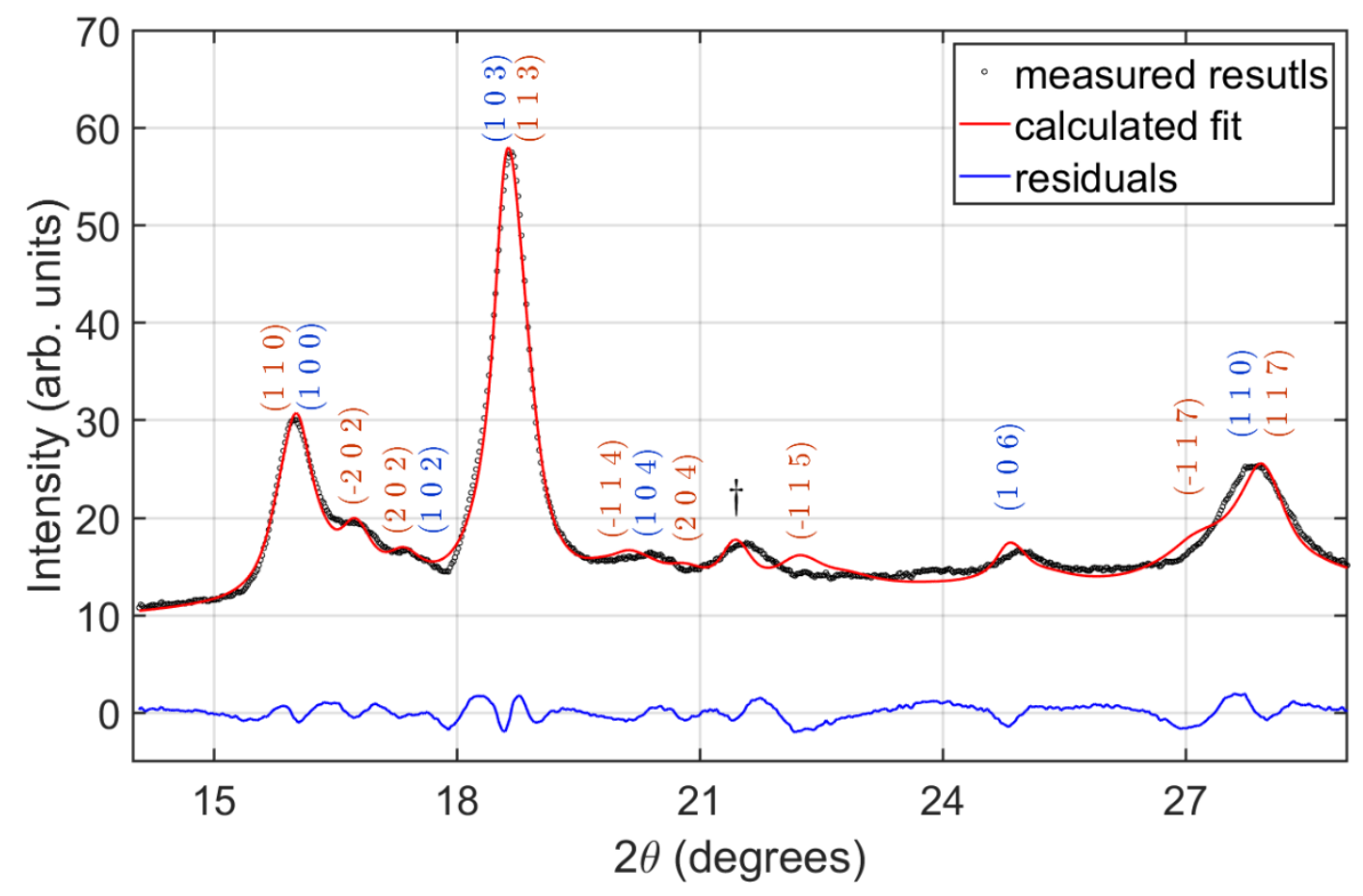

Figure 12: Rietveld analysis of the XRD pattern of $\mathrm{Mo}_{2} \mathrm{GaC}$ at $30 \mathrm{GPa}$ using a mixture of hexagonal ( $P 6_{3} / m m c$, blue indices) and monoclinic ( $C 2 / m$, red indices) structures with iron (dagger) as the only impurity. Data (black circles) are taken from experiment performed; the red line represents the calculated pattern. The blue line represents the residual curve between the measured data and the fitted model. 


\section{V. c. $\quad$ Structural variations}

Following the above-mentioned evidence for possible monoclinic distortion in the $\mathrm{Mo}_{2} \mathrm{GaC}$ structure as a function of pressure above $\sim 15 \mathrm{GPa}$, an attempt was made to identify the cause of this distortion. To that end we calculated the major lattice distances and angles as a function of pressure for the original hexagonal $\left(\mathrm{PG}_{3} / \mathrm{mmc}(\alpha)\right)$ structure, as well as for the three most possible structures that may exist after the transition according to our calculation and measurements, namely, $P 6_{3} / m m c(\beta), C 2 / m, A m m 2(\alpha \beta)$ (Figures S1, and S2 in the supplemental material). In general, all studied parameters change smoothly with pressure, and do not differ much between structures. This is in contrast with the clear jump in structural parameters observed for $\mathrm{Mo}_{2} \mathrm{Ga}_{2} \mathrm{C}$ at much higher pressure ( $48 \mathrm{GPa}$ ) [48]. Moreover, no significant change of slope or discontinuity in the bond lengths is observed unlike what was previously observed for $\mathrm{Mo}_{2} \mathrm{Ga}_{2} \mathrm{C}$ at $\sim 22 \mathrm{GPa}$ [47]. It is worth noting here that the significant change observed in $\mathrm{Mo}_{2} \mathrm{Ga}_{2} \mathrm{C}$ resulted when the Ga layers change their stacking from top-packed double layer to close-packed stacking without changing the $\mathrm{Mo}_{2} \mathrm{C}$ layer $\left(\alpha-\mathrm{Mo}_{2} \mathrm{Ga}_{2} \mathrm{C}\right.$ to $\beta-\mathrm{Mo}_{2} \mathrm{Ga}_{2} \mathrm{C}$ transition [47]). Clearly, such a transition is impossible in the original structure of the $n=1$ MAX phases.

However, an indication for behavioral change in the Mo-Ga-Mo angle (across layers) is observed for the original $\mathrm{Pb}_{3} / \mathrm{mmc}$ structure, and therefore was further studied (Figure 13). It is clear from these additional calculations, that at $\sim 12 \mathrm{GPa}$ it is more energetically favorable for the Mo-Ga-Mo angle in the $\mathrm{P6}_{3} / \mathrm{mmc}$ structure to start increase with pressure rather than to decrease with the latter increase. This pressure is in excellent agreement with the pressure from which the structural transition is observed experimentally. In the case of the other structures this angle either continues to decrease or reaches a plateau. A closer look on the $P 6_{3} / m m c$ structure, with its single free position parameter $\mathrm{Z}_{\mathrm{Mo}}$, reveals that the most significant structural value that correlates with changes in c/a is the Mo-Ga-Mo angle. As the pressure increases c/a can either decrease or increase. An increase in this value, as is the case for $\mathrm{Mo}_{2} \mathrm{GaC}$, will either force the Mo-Ga-Mo angle to increase or $\mathrm{z}_{\mathrm{Mo}}$ to increase to accommodate for the change. However, an increase in $\mathrm{z}_{\mathrm{Mo}}$ will cause an increase in the Mo-Mo bond length within the $\mathrm{Mo}_{2} \mathrm{C}$ carbide layer. Obviously, for the case of $\mathrm{Mo}_{2} \mathrm{GaC}$ it becomes unfavorable energetically above $\sim 12 \mathrm{GPa}$, and the Mo-Ga-Mo angle therefore must increase with increase in pressure (Figure 13). This effect is also accompanied by relatively large increase in c/a as a function of pressure, which is much higher than the observed one (Figure 6c). One possible way to both decrease the Mo-Ga-Mo angle (or keep it constant) and keep the $\mathrm{Mo}_{2} \mathrm{C}$ layer from expanding too much with pressure is to change to monoclinic symmetry and open more structural degrees of freedom. This effect should be further studied experimentally. 


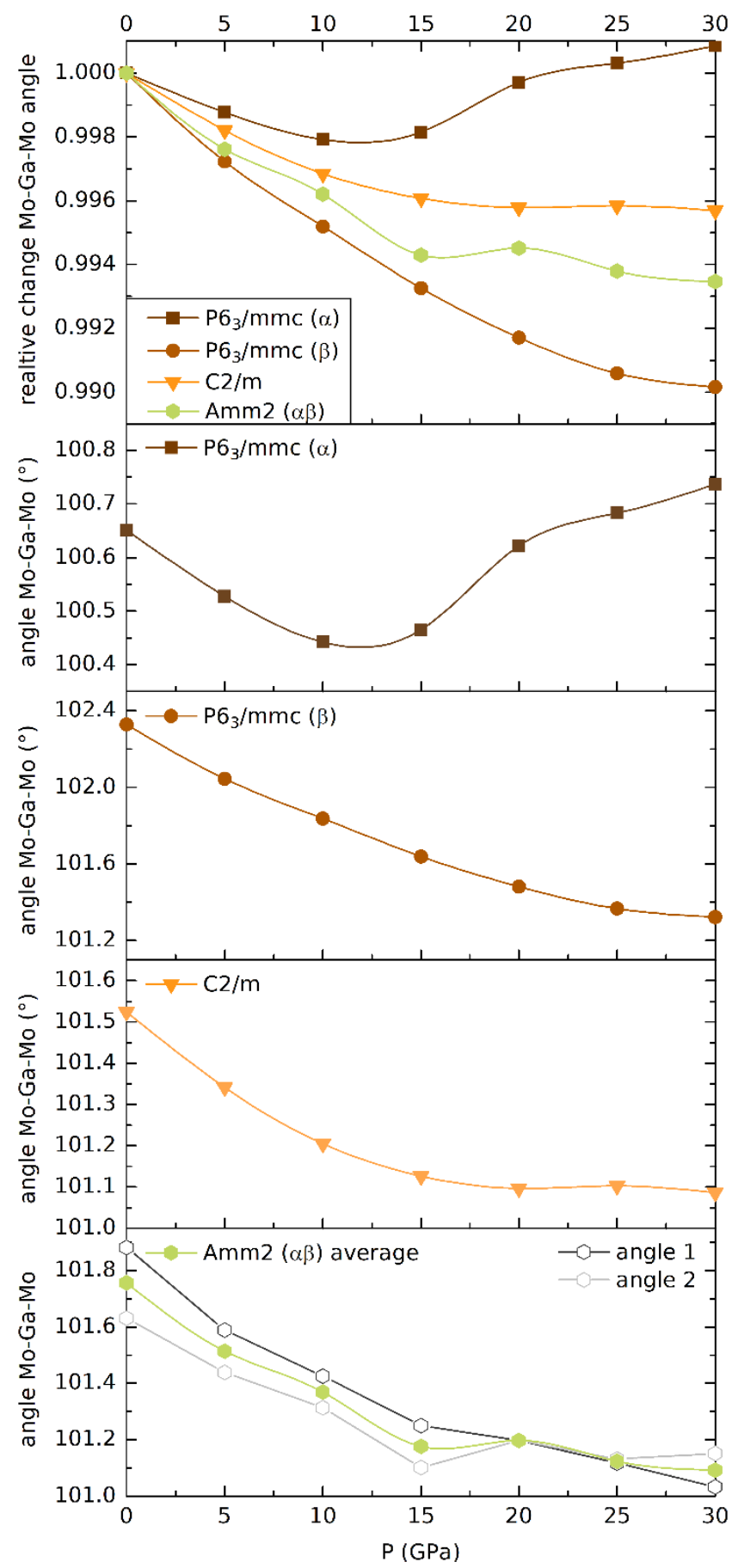

Figure 13: Relative and absolute values of the Mo-Ga-Mo angle (Figure S3) as a function of pressure for the four possible $\mathrm{Mo}_{2} \mathrm{GaC}$ structure discussed in the text. 


\section{V.d. $\quad$ Equation of state (EOS)}

A universal equation of state (EOS) was fitted to the results and from it we estimated the bulk modulus, $\mathrm{B}$, and its derivative. The equation was fitted to the data between 0 and $30 \mathrm{GPa}$ both in compression and decompression as no sign of change between both was seen. The result is shown in Figure 14. The data above $15.7 \mathrm{GPa}$ was calculated using the monoclinic $\mathrm{C} 2 / \mathrm{c}$ phase, even though fitting the results up to $15.7 \mathrm{GPa}$ or using the monoclinic $\mathrm{P} 21 / \mathrm{m}$ or $\mathrm{C} 2 / \mathrm{m}$ above $15.7 \mathrm{GPa}$ did not change the results above the fit uncertainties. Due to the large uncertainties of the measured volume values, and the relatively low maximum pressure of the experiment, a well-defined equation of state was nearly impossible to obtain, because nearly every possible combination of B and its derivative, B', gave similarly acceptable fits. Confining B' to a range of values that previous work has, viz. between 3 and 6 , always resulted in a fit where B was larger by at least $20 \mathrm{GPa}$ than the stiffest experimentally known MAX phase to date, viz. $\mathrm{Ta}_{4} \mathrm{AlC}_{3}$ [29]. Assuming B' to be 4, which is similar to most MAX phases (see Table 1) resulted in a bulk modulus of $295 \pm 25 \mathrm{GPa}$. This means that $\mathrm{Mo}_{2} \mathrm{GaC}$ is the stiffest MAX phase measured under high pressure. The same result is achieved when attempting to fit the results to the hexagonal phase up to $15.7 \mathrm{GPa}$.

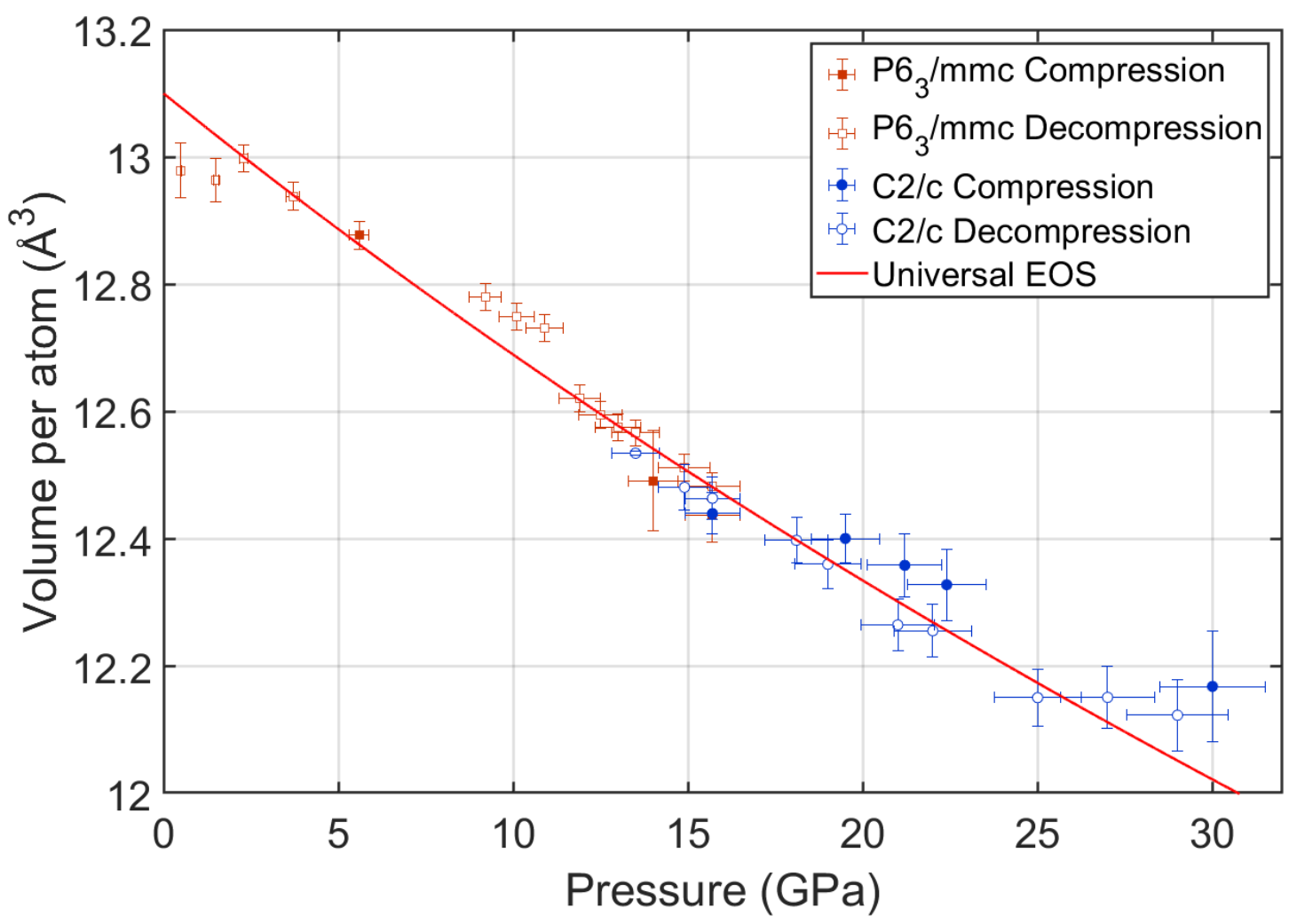

Figure 14: Average volume per atom as a function of pressure. There is no evidence of a change in the volume during the second order phase transition at $\approx 15.7 \mathrm{GPa}$. A universal EOS [49] was fitted to the results. 


\section{Conclusions}

In this work, we measured the compressibility, up to a hydrostatic pressure of $30 \mathrm{GPa}$, of the $\mathrm{Mo}_{2} \mathrm{GaC}$ MAX phase, using the DAC method. In accordance with a recent DFT study, we show that the aaxis is more compressible than the c-axis. Somewhat surprisingly, at $295 \pm 25 \mathrm{GPa}$, the bulk modulus of $\mathrm{Mo}_{2} \mathrm{GaC}$ is the highest reported of all the MAX phases measured to date.

Above $15 \mathrm{GPa}$, a splitting in the $\left(\begin{array}{lll}1 & 0 & 0\end{array}\right)$ reflection occurs suggesting the occurrence of a second order phase transition in which the symmetry of the material decreases from the initial hexagonal structure to a new, and yet unknown, high-pressure phase. The possibility of an impurity in the DAC explaining the high-pressure splitting of the $\left(\begin{array}{lll}1 & 0 & 0\end{array}\right)$ reflection was ruled out, and the best possible explanation found was a transition to a monoclinic structure or even a mixture of both monoclinic and hexagonal phases.

Our theoretical calculations reinforce this hypothesis as they show quite small enthalpy differences $(0.005 \mathrm{eV} /$ atom at $30 \mathrm{GPa})$ between the monoclinic structure and the ambient pressure hexagonal phase. Comparing the experimental results to the calculations clearly show that the experimental lattice dimension favor dimensions of lower than hexagonal symmetry, or, at least strongly disagree with the expected dimensions of the original hexagonal structure. The exact structure of this new phase is still unknown as well as the position of the atoms, but it is most likely that the phase transition involves a relative change in the $\mathrm{a}$ and $\mathrm{b}$ cell parameters. A possible origin of this structural transition can be found within the behavior of the Mo-Ga-Mo angle across layers as a function of pressure.

Among studied structures, the two best candidates for the high-pressure phase were $\mathrm{C} 2 / \mathrm{c}$ and $\mathrm{C} 2 / \mathrm{m}$. The former was found to be the best fit for the results when attempting to fit the XRD results using Rietveld analysis of a single phase, while the latter produced the best fit at $30 \mathrm{GPa}$ when mixed with the hexagonal phase. DFT calculations of the $\mathrm{C} 2 / \mathrm{c}$ phase quickly collapse back to the hexagonal phase, while the $\mathrm{C} 2 / \mathrm{m}$

phase was found to be stable, and at lower enthalpy than the hexagonal phase above $15 \mathrm{GPa}$. Future work needs to take a closer examination at the high-pressure structure.

\section{Supplementary Material}

A comparison of three different bond lengths and two bond angles calculated for four selected structures $\left(\mathrm{P}_{3} / \mathrm{mmc}(\alpha), \mathrm{P} 6_{3} / \mathrm{mmc}(\beta), \mathrm{C} 2 / \mathrm{m}\right.$, and $\mathrm{Amm} 2(\alpha \beta)$ ) on a relative (to $0 \mathrm{GPa}$ ), and absolute scales. 


\section{Acknowledgments}

N.M., R.F., and M.H. acknowledge Eyal Greenberg, Dvir Fadel and Gennady Rafailov for their help in acquiring the ambient pressure XRD pattern.

J.R. acknowledges support from the Knut and Alice Wallenberg (KAW) Foundation for a Fellowship Grant and from the Swedish Research council through Project 642-2013-8020. The calculations were carried out using supercomputer resources provided by the Swedish National Infrastructure for Computing (SNIC) at the National Supercomputer Centre (NSC), the High Performance Computing Center North (HPC2N), and the PDC Center for High Performance Computing.

This work was supported by the National Science Foundation (DMR-1740795).

\section{References}

[1] M. W. Barsoum and T. El-Raghy, American Scientist 89, 334 (2001).

[2] M. W. Barsoum, Progress in Solid State Chemistry 28, 201 (2000).

[3] Z. M. Sun, International Materials Reviews 56, 143 (2011).

[4] M. W. Barsoum, MAX phases: properties of machinable ternary carbides and nitrides (John Wiley \& Sons, 2013).

[5] M. Sokol, V. Natu, S. Kota, and M. W. Barsoum, Trends in Chemistry 1, 210 (2019).

[6] A. Farle, L. Boatemaa, L. Shen, S. Gövert, J. B. W. Kok, M. Bosch, S. Yoshioka, S. van der Zwaag, and W. G. Sloof, Smart Materials and Structures 25, 084019 (2016).

[7] D. J. Tallman, B. Anasori, and M. W. Barsoum, Materials Research Letters 1, 115 (2013).

[8] D. J. Tallman, E. N. Hoffman, E. a. N. Caspi, B. L. Garcia-Diaz, G. Kohse, R. L. Sindelar, and M. W. Barsoum, Acta Materialia 85, 132 (2015).

[9] M. Naguib, J. Come, B. Dyatkin, V. Presser, P.-L. Taberna, P. Simon, M. W. Barsoum, and Y. Gogotsi, Electrochemistry Communications 16, 61 (2012).

[10] B. Anasori, M. R. Lukatskaya, and Y. Gogotsi, Nature Reviews Materials 2, 16098 (2017).

[11] X. Jiang, A. V. Kuklin, A. Baev, Y. Ge, H. Ågren, H. Zhang, and P. N. Prasad, Physics Reports 848, 1 (2020).

[12] C. Hu, C. Li, J. Halim, S. Kota, D. J. Tallman, and M. W. Barsoum, J. Am. Ceram. Soc. 98, 2713 (2015).

[13] C.-C. Lai, H. Fashandi, J. Lu, J. Palisaitis, P. O. Å. Persson, L. Hultman, P. Eklund, and J. Rosen, Nanoscale 9, 17681 (2017).

[14] L. E. Toth, Journal of the Less Common Metals 13, 129 (1967).

[15] I. R. Shein and A. L. Ivanovskii, Physica C: Superconductivity 470, 533 (2010).

[16] I. R. Shein and A. L. Ivanovskii, physica status solidi (b) 248, 228 (2011).

[17] M. A. HADI, M. S. ALI, S. H. NAQIB, and A. K. M. A. ISLAM, International Journal of Computational Materials Science and Engineering 02, 1350007 (2013).

[18] Q.-H. Gao, Z.-J. Xu, L. Tang, J. Li, A. Du, Y.-D. Guo, and Z.-J. Yang, Journal of Applied Physics 119, 015901 (2016).

[19] Z. J. Yang, L. Tang, A. M. Guo, X. L. Cheng, Z. H. Zhu, and X. D. Yang, Journal of Applied Physics 114, 083506 (2013).

[20] Z. J. Yang, J. Li, R. F. Linghu, X. L. Cheng, and X. D. Yang, Journal of Alloys and Compounds 574, 573 (2013).

[21] C. Hu et al., Chemical Communications 51, 6560 (2015).

[22] C. C. Lai et al., Acta Materialia 99, 157 (2015). 
[23] B. Manoun, S. K. Saxena, H. P. Liermann, R. P. Gulve, E. Hoffman, M. W. Barsoum, G. Hug, and C. S. Zha, Applied Physics Letters 85, 1514 (2004).

[24] B. Manoun, O. D. Leaffer, S. Gupta, E. N. Hoffman, S. K. Saxena, J. E. Spanier, and M. W. Barsoum, Solid State Communications 149, 1978 (2009).

[25] B. Manoun, R. P. Gulve, S. K. Saxena, S. Gupta, M. W. Barsoum, and C. S. Zha, Physical Review B 73, 024110 (2006).

[26] B. Manoun, F. X. Zhang, S. K. Saxena, T. El-Raghy, and M. W. Barsoum, Journal of Physics and Chemistry of Solids 67, 2091 (2006).

[27] M. Bouchaib, A. Sharam, G. Surojit, K. S. Surendra, and W. B. Michel, Journal of Physics: Condensed Matter 19, 456218 (2007).

[28] B. Manoun, S. Kulkarni, N. Pathak, S. K. Saxena, S. Amini, and M. W. Barsoum, Journal of Alloys and Compounds 505, 328 (2010).

[29] B. Manoun, S. K. Saxena, T. El-Raghy, and M. W. Barsoum, Applied Physics Letters 88, 201902 (2006).

[30] B. Manoun, S. K. Saxena, and M. W. Barsoum, Applied Physics Letters 86, 101906 (2005).

[31] B. Manoun, H. Yang, S. K. Saxena, A. Ganguly, M. W. Barsoum, B. El Bali, Z. X. Liu, and M. Lachkar, Journal of Alloys and Compounds 433, 265 (2007).

[32] M. Bouchaib, Z. Fuxiang, K. S. Surendra, G. Surojit, and W. B. Michel, Journal of Physics: Condensed Matter 19, 246215 (2007).

[33] B. Manoun, H. P. Liermann, R. P. Gulve, S. K. Saxena, A. Ganguly, M. W. Barsoum, and C. S. Zha, Applied Physics Letters 84, 2799 (2004).

[34] B. Manoun, S. K. Saxena, G. Hug, A. Ganguly, E. N. Hoffman, and M. W. Barsoum, Journal of Applied Physics 101, 113523 (2007).

[35] E. Sterer, M. P. Pasternak, and R. D. Taylor, Review of Scientific Instruments 61, 1117 (1990).

[36] R. Boehler and K. De Hantsetters, High Pressure Research 24, 391 (2004).

[37] P. Thompson, D. E. Cox, and J. B. Hastings, J. Appl. Crystallogr. 20, 79 (1987).

[38] H. Rietveld, J. Appl. Crystallogr. 2, 65 (1969).

[39] J. Rodríguez-Carvajal, Physica B: Condensed Matter 192, 55 (1993).

[40] G. Kresse and J. Furthmuller, Physical Review B 54, 11169 (1996).

[41] J. P. Perdew, K. Burke, and M. Ernzerhof, Physical Review Letters 77, 3865 (1996).

[42] H. J. Monkhorst and J. D. Pack, Physical Review B 13, 5188 (1976).

[43] E. Parthe and V. Sadogopan, Acta Crystallographica 16, 202 (1963).

[44] H. K. Mao, W. A. Bassett, and T. Takahashi, Journal of Applied Physics 38, 272 (1967).

[45] T. Hahn, International Tables for Crystallography, Volume A: Space Group Symmetry (Springer, Dordrecht, The Netherlands, 2005).

[46] T. Liao, J. Wang, and Y. Zhou, Journal of Physics: Condensed Matter 18, 6183 (2006).

[47] J. Niu, H. Zhang, Y. Wu, C. Hu, and X. Wu, Journal of Applied Physics 124, 085903 (2018).

[48] Z.-J. Yang, Q.-H. Gao, Y.-D. Guo, Z.-J. Xu, and L. Tang, Modern Physics Letters B 30, 1650105 (2016).

[49] J. H. Rose, J. R. Smith, F. Guinea, and J. Ferrante, Physical Review B 29, 2963 (1984). 